\title{
The C161T Polymorphism in Peroxisome Proliferator-Activated Receptor $\gamma 2$, but Not Pro12Ala, Is Associated with Diabetic Retinopathy in Type 2 Diabetes Mellitus in an Egyptian Population
}

\author{
Ragaa Abelkader Ramadan ${ }^{*}$, Moyassar Ahmad Zaki', Rania Mohamed El Sharkawy1, \\ Lubna Mohamed Desouky², Marwa Ahmed Madkour3, \\ Karim Mahmoud Nabil Mohamed Kamel ${ }^{4}$ \\ ${ }^{1}$ Chemical Pathology Department, Medical Research Institute, Alexandria University, Alexandria, Egypt \\ ${ }^{2}$ Department of Human Genetics, Medical Research Institute, Alexandria University, Alexandria, Egypt \\ ${ }^{3}$ Clinical and Experimental Internal Medicine Department, Medical Research Institute, Alexandria University, \\ Alexandria, Egypt \\ ${ }^{4}$ Department of Ophthalmology, Faculty of Medicine, Alexandria University, Alexandria, Egypt \\ Email: "ragaa.abdelkader@gmail.com
}

Received 10 September 2015; accepted 21 December 2015; published 25 December 2015

Copyright (C) 2016 by authors and Scientific Research Publishing Inc.

This work is licensed under the Creative Commons Attribution International License (CC BY). http://creativecommons.org/licenses/by/4.0/

(c) (i) Open Access

\section{Abstract}

Objectives: Diabetic retinopathy (DR) is one of the most common microvascular complications of type 2 diabetes mellitus (T2DM). It is multifactorial with the contribution of multiple genetic factors. We questioned the association of polymorphisms in the peroxisome proliferator-activated receptor $y^{2}$ (PPARy2) gene (Pro12Ala and C161T) with DR in an Egyptian population. Methods: This case control study included one hundred healthy individuals and 252 T2DM among them 122 with DR and 130 without DR. Genotyping was done by polymerase chain reaction restriction fragment length polymorphism (PCR-RFLP). Results: The Pro12Ala Ala allele was associated with decreased risk of DR with an odds ratio (OR) of $0.484,95 \%$ confidence interval (CI) $(0.254-0.920)$, and a p value $=0.024$. The C161T T allele was associated with increased risk of $D R$ with $O R=2.593$, $95 \%$ CI (1.672 - 4.020), $p<0.001$. However, when considering other covariates such as glycosylated hemoglobin $\left(\mathrm{HbA}_{1 \mathrm{c}}\right)$ in multivariate regression analysis only $\mathrm{C161T}$ was associated with increased risk of DR with $\mathrm{OR}=3.479,95 \% \mathrm{CI}(1.907-6.346), \mathrm{p}<0.001$, while the significant association with Pro12Ala was lost. $\mathrm{HbA}_{1 \mathrm{c}}$ was higher in Pro/Pro genotype when compared to those with

\footnotetext{
${ }^{*}$ Corresponding author.
} 
Ala/Ala and Pro/Ala genotypes. Conclusion: We report that T allele of C161T increased risk of DR in the studied population. Further studies are warranted to investigate functional implications of polymorphisms of the PPAR- $\gamma$ gene in DR development.

\section{Keywords}

\section{Type 2 Diabetes Mellitus, Diabetic Retinopathy, Polymorphism, PPARy2, Pro12Ala, C161T}

\section{Introduction}

Diabetic retinopathy (DR) is a common microvascular diabetic complication (MVD) [1], and is the fifth most common cause of irreversible loss of vision in adults [2]. Duration of diabetes and chronic hyperglycemia are among the factors that may increase the risk of DR [1]. But the occurrence of diabetic complications despite of good glycemic control, and the variations in the prognosis in diabetics with similar metabolic dysregulation have suggested the contribution of other risk factors namely genetic ones [3]. Familial aggregation, ethnic differences and heritability pinpointed the role of genetics in the etiology of DR. A genome-wide association study in Chinese has identified loci in genes related to insulin regulation, inflammation and apoptosis, as potential susceptibility genes in the development of DR. These associations were independent of glycosylated hemoglobin $\left(\mathrm{HbA}_{1 \mathrm{c}}\right)$ level and duration of diabetes [4].

The peroxisome proliferator-activated receptor gamma $\left(P P A R_{\gamma}\right)$ gene is located on chromosome 3p25.3, and it encodes a protein that belongs to the nuclear hormone receptor superfamily of ligand-regulated transcription factors [5]. PPARY2 is predominantly expressed in adipose tissue and it regulates the transcription and expression of numerous target genes implicated in adipocyte differentiation, lipid metabolism and insulin-mediated glucose uptake in peripheral tissues, and hence it has been the focus of diabetes research [6]. Recently, genome wide association studies have confirmed that mutations of PPARy are associated with monogenic subsets of non-autoimmune diabetes [7]. Several polymorphisms in PPARy2 have been identified. The most common of which is Pro12Ala (rs1801282), which codes for proline instead of alanine at exon 2 [5]. Another polymorphism is the silent mutation C161T (rs3856806), at exon 6 that codes for histidine amino acid [8]. PPAR have been studied in relation to ocular diseases. Retinal expression of PPAR $\gamma$ was suppressed in experimental models of diabetes and in endothelial cells treated with high glucose [9]. Muranaka et al. showed that upon ligand activation, PPAR $\gamma$ reduced leukostasis and leakage in retinal vasculature [10]. However, results of the association between PPAR $\gamma$ polymorphisms and DR have been inconsistent in different populations [11]-[13].

Herein, we carried out this case control study to determine the possible association of PPARY2 Pro12Ala and C161T polymorphisms with DR in type 2 diabetes mellitus (T2DM), and their relation to markers of glycemic control.

\section{Methods}

\subsection{Population Studied}

Diabetics were recruited from the Diabetes Clinic in the Teaching Hospital of Medical Research Institute, Alexandria University from November 2012 till September 2014. T2DM was diagnosed based on the American Diabetes Association criteria [1]. The study was explained to all participants and written informed consents were required. The study was approved by the local ethics committee of the institute in accordance with The Code of Ethics of the World Medical Association (Declaration of Helsinki) for experiments involving humans. All diabetics were receiving oral hypoglycemic agents. Exclusion criteria included: T2DM with less than 10 years duration, type 1 diabetes, secondary diabetes, smoking, hypertension, pregnancy.

\subsection{Examination and Blood Sampling}

All subjects had a standardized physical and ophthalmological examination. Ophthalmological examination included visual acuity, slit lamp examination, and funduscopy. Retinopathy was defined as stages III or IV on funduscopy or as history of laser therapy. Patients were stratified as either non-retinopathy ( $\mathrm{DR}^{-}$), who were considered the control group, or with diabetic retinopathy $\left(\mathrm{DR}^{+}\right)$; the latter including both non-proliferative and 
proliferative.

A morning blood sample following a 12 hours fasting period was collected in EDTA coated and serum separator vacutainer tubes. The Whole EDTA blood was used for genomic DNA extraction and determination of glycosylated haemoglobin $\left(\mathrm{HbA}_{1 \mathrm{c}}\right)$. Serum levels of selected biochemical parameters were determined on the Olympus AU400 Clinical Chemistry Analyzer (Beckman Coulter Inc., Brea, CA, USA)

\subsection{Analysis of Pro12Ala and C161T Polymorphism of the PPARy2 Gene}

Genomic DNA was extracted using a commercially available kit (Qiagen). The concentration and purity of extracted DNA were determined by NanoDrop ${ }^{\mathrm{TM}} 1000$ spectrophotometer (Thermo Fisher Scientific). The polymerase chain reactions for the PPARY2 gene polymorphisms were carried out in a Veriti thermal cycler (Applied Biosystems) according to the methods described by Liu et al. [14]. The resultant RFLP digestion products were visualized by electrophoresis on 3\% agarose gel stained with ethidium bromide for visualization under UV light. In $5 \%$ of the samples genotyping was performed in duplicate and was fully concordant.

\subsection{Statistical Analysis}

Statistical analyses were analyzed by SPSS.20. Descriptive measures were done for all variables and a p-value less than 0.05 was considered statistically significant. The Student's t-test, chi-squared $\left(\chi^{2}\right)$ test, and Fisher exact test were used to assess the general characteristics between groups. Allele frequencies of polymorphisms were determined by using direct gene counting. The genotype distribution for each SNP was evaluated for HardyWeinberg equilibrium. The strength of association between variant alleles and their susceptibility to the disease was assessed using univariate regression analysis. Odds ratios (ORs) with $95 \%$ confidence intervals and chi-square tests were calculated. A multivariate logistic regression model was used to test the association of genotypes and DR, considering covariates of gender, age, duration of T2D, body mass index (BMI), fasting plasma glucose, total cholesterol and glycosylated $\mathrm{HbA}_{1 \mathrm{c}}$.

\section{Results}

The study included one hundred healthy individuals and 252 unrelated type 2 diabetics; classified according to presence of DR into 130 (51.6\%) diabetics without retinopathy (DR ) and 122 (48.4\%) diabetics with retinopathy $\left(\mathrm{DR}^{+}\right)$. DR was more frequent in males than females, but this did not reach the level of statistical significance $(p=0.061)$. $\mathrm{DR}^{+}$patients had higher glycosylated hemoglobin $\left(\mathrm{HbA}_{1 c}\right)$ than $\mathrm{DR}^{-}(\mathrm{p}<0.001)$ (Table 1$)$.

Genotype groups were in accordance with the Hardy-Weinberg equilibrium in the studied single nucleotide polymorphisms (SNPs); Pro12Ala $(\mathrm{p}=0.098)$ and C161T $(\mathrm{p}=0.244)$ in healthy individuals. Ala allele carriers either Ala/Ala or Pro/Ala were more frequent in $\mathrm{DR}^{-}$than $\mathrm{DR}^{+}$. The Ala allele was associated with decreased

Table 1. Baseline and laboratory characteristics of the studied population.

\begin{tabular}{|c|c|c|c|c|}
\hline \multirow{2}{*}{ Variables } & \multirow{2}{*}{ Whole diabetics } & \multicolumn{2}{|c|}{ Retinopathy } & \multirow{2}{*}{$\mathrm{p}$ value } \\
\hline & & $\mathrm{DR}^{-}$ & $\mathrm{DR}^{+}$ & \\
\hline Number (\%) & 252 & $130(51.6)$ & $122(48.4)$ & \\
\hline Gender (\% men) & $121(48.0)$ & 55 (42.3) & $66(54.1)$ & 0.061 \\
\hline Age (years) & $51.70 \pm 7.19$ & $51.83 \pm 7.18$ & $51.56 \pm 7.22$ & 0.764 \\
\hline Duration of diabetes (years) & $13.23 \pm 3.28$ & $13.32 \pm 3.31$ & $13.13 \pm 3.27$ & 0.657 \\
\hline BMI $\left(\mathrm{Kg} / \mathrm{m}^{2}\right)$ & $31.41 \pm 4.13$ & $31.30 \pm 4.11$ & $31.52 \pm 4.17$ & 0.685 \\
\hline Glucose (mg/dl) & $179.35 \pm 60.99$ & $175.06 \pm 62.76$ & $183.92 \pm 58.95$ & 0.250 \\
\hline $\mathrm{HbA}_{1 \mathrm{C}}(\%)$ & $8.72 \pm 1.99$ & $7.98 \pm 1.57$ & $9.51 \pm 2.10$ & $<0.001^{*}$ \\
\hline Total cholesterol (mg/dl) & $217.31 \pm 32.36$ & $221.22 \pm 27.51$ & $213.14 \pm 36.48$ & $0.049^{*}$ \\
\hline Triglycerides (mg/dl) & $157.85 \pm 43.62$ & $158.95 \pm 46.01$ & $156.69 \pm 41.07$ & 0.682 \\
\hline HDL-C (mg/dl) & $43.80 \pm 9.36$ & $44.03 \pm 9.09$ & $43.55 \pm 9.67$ & 0.684 \\
\hline LDL-C (mg/dl) & $141.90 \pm 32.29$ & $145.32 \pm 26.60$ & $138.25 \pm 37.19$ & 0.086 \\
\hline
\end{tabular}

*: Statistically significant, $\mathrm{DR}^{-}$: no diabetic retinopathy, $\mathrm{DR}^{+}$: diabetic retinopathy, $\mathrm{BMI}$ : body mass index, HbA HDL-C, LDL-C: high and low density lipoprotein cholesterol; p: comparison between $\mathrm{DR}^{-}$and $\mathrm{DR}^{+}$. 
risk of DR with odds ratio $0.484,95 \%$ confidence interval (CI) $(0.254-0.920), \mathrm{p}=0.024$. On the other hand, $\mathrm{T}$ allele carriers either TT or CT were more frequent in $\mathrm{DR}^{+}$than $\mathrm{DR}^{-}$. The $\mathrm{T}$ allele was associated with increased risk of DR with OR $=2.593,95 \%$ CI $(1.672-4.020), \mathrm{p}<0.001$ (Table 2).

We performed a logistic regression model to adjust the OR for the presence of variant alleles and DR. The model included male gender as a categorical variable, while duration of diabetes, fasting glucose, BMI, total cholesterol and $\mathrm{HbA}_{1 \mathrm{c}}$ were analyzed as continuous variables. Predictors of DR from this model were C161T variant OR = 3.479, 95\% CI (1.907 - 6.346), $\mathrm{p}<0.001$ followed by $\mathrm{HbA}_{1 \mathrm{c}} \mathrm{OR}=1.58$, 95\% CI (1.334 - 1.872), $\mathrm{p}$ $<0.001$, while the significant association with Pro12Ala variant was lost (Table 3).

We analyzed the distribution of clinical and metabolic parameters according to the studied genotypes in the whole diabetic group. Since the number of homozygous patients (Ala/Ala and TT) was small, they were combined with the heterozygous patients (Pro/Ala and CT) respectively. Diabetics with Pro/Pro genotype had significantly higher $\mathrm{HbA}_{1 \mathrm{c}}$ compared to those with Pro/Ala $+\mathrm{Ala} / \mathrm{Ala}(\mathrm{p}=0.003)$, also those with CC genotype had significantly higher BMI compared to those with CT + TT $(\mathrm{p}=0.025)$ (Table 4).

Table 2. The genotype and allele distribution of Pro12Ala and C161T polymorphisms of PPARY2 in the studied groups.

\begin{tabular}{|c|c|c|c|c|c|c|c|}
\hline & Genotypes/alleles & $\begin{array}{l}\text { Healthy } \\
(\mathrm{n}=100)\end{array}$ & $\begin{array}{l}\text { Whole diabetics } \\
\qquad(\mathrm{n}=252)\end{array}$ & $\begin{array}{c}\mathrm{DR}^{-} \\
(\mathrm{n}=130)\end{array}$ & $\begin{array}{c}\mathrm{DR}^{+} \\
(\mathrm{n}=122)\end{array}$ & $\mathrm{p}$ & OR (95\% CI) \\
\hline \multirow{6}{*}{$\begin{array}{l}\frac{\pi}{d} \\
\stackrel{1}{1} \\
\overline{0} \\
\vdots\end{array}$} & Pro/Pro® & 72 & $210(83.3)$ & $102(78.5)$ & $108(88.5)$ & & \\
\hline & Pro/Ala & 23 & 38 (15.1) & 25 (19.2) & $13(10.7)$ & 0.054 & $0.491(0.238-1.012)$ \\
\hline & Ala/Ala & 5 & $4(1.6)$ & $3(2.3)$ & $1(0.8)$ & 0.320 & $0.315(0.032-3.076)$ \\
\hline & Pro/Pro vs Pro/Ala - Ala/Ala & 28 & $42(16.7)$ & $28(21.5)$ & $14(11.5)$ & $0.035^{*}$ & $0.472(0.235-0.947)$ \\
\hline & Pro allele ${ }^{\circledR}$ & $167(83.5)$ & $458(90.8)$ & $229(88.1)$ & 229 (93.9) & & \\
\hline & Ala allele & 33 (16.5) & $46(9.1)$ & 31 (11.9) & $15(6.1)$ & $0.024^{*}$ & $0.484(0.254-0.920)$ \\
\hline \multirow{6}{*}{$\begin{array}{l}\vec{E} \\
\overrightarrow{0} \\
\vec{U}\end{array}$} & $\mathrm{C} / \mathrm{C} \circledast$ & 57 & 149 (59.1) & 95 (73.1) & $61(50)$ & & \\
\hline & $\mathrm{C} / \mathrm{T}$ & 34 & 85 (33.7) & $32(24.6)$ & 47 (38.5) & $0.002^{*}$ & $2.287(1.316-3.974)$ \\
\hline & $\mathrm{T} / \mathrm{T}$ & 9 & $18(7.1)$ & $3(2.3)$ & $14(11.5)$ & $0.003^{*}$ & $7.268(2.05-26.34)$ \\
\hline & $\mathrm{C} / \mathrm{C} \AA$ vs $\mathrm{C} / \mathrm{T}-\mathrm{T} / \mathrm{T}$ & 43 & $103(40.8)$ & 35 (26.9) & $61(50)$ & $<0.001^{*}$ & $2.714(1.605-4.591)$ \\
\hline & C allele ${ }^{\circledR}$ & $148(74)$ & $383(76)$ & $222(85.4)$ & 169 (69.3) & & \\
\hline & $\mathrm{T}$ allele & $52(26)$ & $121(24)$ & 38 (14.6) & 75 (30.7) & $<0.001^{*}$ & $2.593(1.672-4.020)$ \\
\hline
\end{tabular}

*: Statistically significant, $\mathrm{DR}^{-}$: no diabetic retinopathy, $\mathrm{DR}^{+}$: diabetic retinopathy, $\mathrm{OR}$ : Odds ratio between $\mathrm{DR}^{-}$and $\mathrm{DR}^{+}$, CI: confidence interval.

Table 3. Multiple logistic regression analysis for the association between diabetic retinopathy, gene polymorphisms and other covariates in type 2 diabetic patients.

\begin{tabular}{ccc}
\hline Covariates & \multicolumn{2}{c}{ Diabetic Retinopathy } \\
\cline { 2 - 3 } Gender & $\mathrm{p}$ & OR (95\%CI) \\
Age & 0.451 & $0.804(0.456-1.418)$ \\
Duration of diabetes (years) & 0.818 & $0.995(0.956-1.036)$ \\
BMI (Kg/m $\left.{ }^{2}\right)$ & 0.845 & $1.009(0.920-1.107)$ \\
Glucose (mg/dl) & 0.431 & $1.029(0.958-1.105)$ \\
HbA 1 (\%) & 0.887 & $1.000(0.996-1.005)$ \\
Total cholesterol (mg/dl) & $<0.001^{*}$ & $1.580(1.334-1.872)$ \\
Pro12Ala & 0.090 & $0.992(0.983-1.001)$ \\
C161T & 0.143 & $0.542(0.238-1.231)$ \\
\hline
\end{tabular}

*: Statistically significant, BMI: body mass index, $\mathrm{HbA}_{1 c}$ : glycosylated haemoglobin. 
Table 4. Baseline and laboratory characteristics of diabetic patients according to their PPARy2 Pro12Ala and C161T genotypes.

\begin{tabular}{|c|c|c|c|c|c|c|}
\hline \multirow{2}{*}{ Items } & \multicolumn{2}{|c|}{ Pro12Ala } & \multirow{2}{*}{$\mathrm{p}$} & \multicolumn{2}{|c|}{$\mathrm{C} 161 \mathrm{~T}$} & \multirow{2}{*}{$\mathrm{p}$} \\
\hline & Pro/Pro & Pro/Ala + Ala/Ala & & CC & $\mathrm{CT}+\mathrm{TT}$ & \\
\hline Number (\%) & $210(83.3)$ & $42(16.7)$ & & $156(61.9)$ & $96(38.1)$ & \\
\hline Gender (\% men) & $106(50.5)$ & $15(35.7)$ & 0.080 & $71(45.5)$ & $50(52.1)$ & 0.311 \\
\hline Age (years) & $51.66 \pm 7.37$ & $51.90 \pm 6.29$ & 0.839 & $52.24 \pm 7.36$ & $50.81 \pm 6.85$ & 0.125 \\
\hline Duration of diabetes (years) & $13.08 \pm 3.19$ & $13.95 \pm 3.66$ & 0.116 & $13.52 \pm 3.44$ & $12.75 \pm 2.95$ & 0.071 \\
\hline BMI & $31.47 \pm 4.17$ & $31.08 \pm 3.96$ & 0.578 & $31.84 \pm 4.43$ & $30.70 \pm 3.51$ & $0.025^{*}$ \\
\hline Glucose (mg/dl) & $179.70 \pm 62.50$ & $177.57 \pm 53.4$ & 0.837 & $173.92 \pm 61.71$ & $188.18 \pm 59.05$ & 0.071 \\
\hline $\mathrm{HbA}_{1 \mathrm{C}}(\%)$ & $8.89 \pm 1.95$ & $7.89 \pm 2.01$ & $0.003^{*}$ & $8.74 \pm 2.13$ & $8.68 \pm 1.76$ & 0.819 \\
\hline Total cholesterol (mg/dl) & $216.81 \pm 32.69$ & $219.76 \pm 30.93$ & 0.591 & $214.28 \pm 33.98$ & $222.22 \pm 29.04$ & 0.058 \\
\hline Triglycerides (mg/dl) & $156.31 \pm 43.63$ & $165.55 \pm 43.24$ & 0.211 & $160.58 \pm 43.62$ & $153.42 \pm 43.48$ & 0.206 \\
\hline HDL-C (mg/dl) & $44.25 \pm 9.40$ & $41.55 \pm 8.94$ & 0.088 & $43.47 \pm 9.58$ & $44.32 \pm 9.02$ & 0.486 \\
\hline LDL-C (mg/dl) & $141.26 \pm 32.69$ & $145.10 \pm 30.41$ & 0.482 & $138.95 \pm 34.44$ & $146.69 \pm 27.97$ & 0.065 \\
\hline
\end{tabular}

*: Statistically significant, BMI: body mass index, $\mathrm{HbA}_{1 c}$ : glycosylated haemoglobin, HDL-C, LDL-C: high and low density lipoprotein cholesterol.

\section{Discussion}

In this case-control study, we showed a significant association between $P P A R \gamma 2 \mathrm{C} 161 \mathrm{~T}$ and risk of $\mathrm{DR}$. The pathophysiology of DR is explained through several pathways: excessive production of advanced glycation end products, and increased oxidative stress with resulting inflammation, angiogenesis and apoptosis. Actually $P P A R y$ have a key role in these aforementioned mechanisms [15].

The prevalence of Ala allele of Pro12Ala shows great diversity among populations ranging from $2 \%-18 \%$ in healthy people, coinciding with our frequency of $16.5 \%$ in non diabetics healthy volunteers [16]. On the other hand, Ala allele had frequencies of $6.1 \%$, and $11.9 \%$ in patients with DR, and patients without DR patients respectively in the current work. Our reported frequencies were lower than the ones reported by meta-analysis of Ma et al., who concluded that the prevalence of the Ala allele was $10.28 \%$ in DM2 with DR and $19.47 \%$ in DM2 without DR. They reported population based differences, where the frequency of the Ala allele was higher in Caucasians populations (27.09\%) than in Asians (7.56\%) [2]. One interesting explanation for this heterogeneity involved ethnic differences in dietary habits where a suggested gene-nutrient interaction based on the ratio of polyunsaturated to saturated fats determined the association between the Pro12Ala polymorphism and BMI, hence the protective effect of the Ala allele was greater in those with lower BMI [17].

Although several studies proposed protective roles for Ala allele against the development of DR, through sensitization of insulin, inhibition of lipid oxidation and reduction of oxidative stress that contributes to insulin resistance [2] [18]-[20], yet the association of Pro12Ala with DR is controversial. In our study although univariate analysis showed a significant association of Pro12Ala with DR, multivariate analysis resulted in loss of this association when considering other covariates. Likewise, Malecki et al. reported no association in non-stratified analysis. But when they classified their diabetic cases according to duration of diabetes, they found a protective significant role of Ala allele, although this association was independent when considering other covariates [21]. In Caucasians, two studies failed to prove any significant association between Pro12Ala and DR [11] [22].

Another polymorphic site examined in the present study was $P P A R \gamma 2 \mathrm{C} 161 \mathrm{~T}$. The frequency of $\mathrm{T}$ allele in our study (26\% in healthy volunteers) was close to that reported in Tunisians [23], but lower values were reported by others; $0 \%-7 \%$ in Caucasians [24] and $12 \%$ in Chinese [25]. In the current study we report, for the first time, that $P P A R{ }^{2} \mathrm{C} 161 \mathrm{~T}$ is an independent factor for DR. Multivariate regression analysis showed that $\mathrm{T}$ allele was associated with increased risk of DR with OR $=3.479$, 95\% CI (1.907 - 6.346), p $<0.001$. Nevertheless, this significant association was independent of $\mathrm{HbA}_{1 \mathrm{c}}$ and diabetes duration.

C161T polymorphism has been studied in relation to one of the major diabetic complications which are coronary artery diseases (CAD), but results were controversial. Some authors proved a significant association with 
CAD independent of BMI and lipid profile and even suggested a direct local vascular wall effect [8] [26], while others could not confirm it [27] [28]. However, a meta-analysis by Ding et al. concluded that $\mathrm{T}$ allele carriers had marginally increased susceptibility of CAD [29]. Beyond the role of PPARy2 variants in body metabolism, C161T polymorphism was related to colonic adenomas [30], colorectal cancers [31], ulcerative colitis [32] and low peak bone mass [33].

Although the pathogenesis of DR is still not completely resolved, a pivotal role has been attributed to insulin resistance. This appears logical because the retina is not only one of the prime insulin targets, but it also expresses basal insulin receptor/Akt signaling pathway [34]. Given the role of PPAR 2 in glucose and lipid metabolism, C161T polymorphism has been studied in relation to insulin resistance, but researches was either confirming [14] [35] or denying such association [36] [37].

Being a silent mutation, functional significance of C161T polymorphism and its effect on PPAR 2 expression may seem hard to explain. One of the earliest explanations was suggested by Meirhaeghe et al. when they reported a significant association between C161T polymorphism and circulating leptin levels in obese subjects. In their study, obese subjects with at least one T allele (CT + TT) had higher plasma leptin levels than subjects with homozygous CC and this was independent of BMI [38]. Interestingly, significant increases of serum and vitreous leptin levels were found in DR in several studies [39]-[41]. Apparently the pathogenesis of DR is multifactorial with interaction of several pathways that requires further research.

We investigated whether the studied SNPs were reflected on the related biochemical parameters of the subjects. The Ala carriers had lower $\mathrm{HbA}_{1 \mathrm{c}}$, while the $\mathrm{T}$ allele carriers had lower $\mathrm{BMI}$, but we did not find any association between the genotypes versus lipid profile. The influence of different varients of PPARy on demographic and biochemical criteria was debatable in various studies [37] [42]-[44].

Nevertheless, certain considerations need to be addressed in this study. The subjects were selected from an outpatient clinic, rather than chosen randomly from the surrounding community. Also, it was hard to differentiate simple association of the polymorphism from the possibility of linkage disequilibrium. Finally, conventional categorization of the cases into non-proliferative, pre-proliferative and proliferative DR (with/without macular edema) was not performed to avoid impairment of statistical power of the study. Thus, further replication studies targeting polygenic and haplotype-based effects with larger population are needed because a single gene has a modest effect size on disease susceptibility which is incremented with interaction with other genes and/or environmental factors.

In conclusion, the study reports for the first time the association of C161T polymorphism with DR, implicating the T-allele in its pathogenesis. In fact, the PPAR $\gamma$ agonists (thiazolidinediones, TZDs) currently used for the treatment of insulin resistance are now perceived as novel adjuvant in treatment of ocular diseases. Owing to their anti-inflammatory, anti-atherogenic, neuroprotective, and antioxidative effects, TZDS may have therapeutic potential in diabetic microvascular complications such as DR [45]. But still the undesirable side effects of TZDs should be weighed against their protective role. Whether TZDs might be more effective or cause fewer side effects in patients carrying specific PPAR $\gamma$ polymorphisms is a point of future research in clinical studies with the concept of personalized medicine.

\section{Disclosure}

Authors have not conflict of interest to disclose.

\section{References}

[1] American Diabetes Association (2014) Standards of Medical Care in Diabetes-2014. Diabetes Care, 37, S14-S80. http://dx.doi.org/10.2337/dc14-S014

[2] Ma, J., Li, Y., Zhou, F., Xu, X., Guo, G. and Qu, Y. (2012) Meta-Analysis of Association between the Pro12Ala Polymorphism of the Peroxisome Proliferator-Activated Receptor- $\gamma 2$ Gene and Diabetic Retinopathy in Caucasians and Asians. Molecular Vision, 18, 2352-2360.

[3] Granier, C., Makni, K., Molina, L., Jardin-Watelet, B., Ayadi, H. and Jarraya, F. (2008) Gene and Protein Markers of Diabetic Nephropathy. Nephrology Dialysis Transplantation, 23,792-799. http://dx.doi.org/10.1093/ndt/gfm834

[4] Sheu, W.H., Kuo, J.Z., Lee, I.T., Hung, Y.-J., Lee, W.-J., Tsai, H.-Y., et al. (2013) Genome-Wide Association Study in a Chinese Population with Diabetic Retinopathy. Human Molecular Genetics, 22, 3165-3173. http://dx.doi.org/10.1093/hmg/ddt161 
[5] Youssef, S.M., Mohamed, N., Afef, S., Khaldoun, B.H., Fadoua, N., Fadhel, N.M., et al. (2014) Combined Effects of the C161T and Pro12Ala PPAR 2 Gene Variants with Insulin Resistance on Metabolic Syndrome: A Case-Control Study of a Central Tunisian Population. Journal of Molecular Neuroscience, 52, 487-492.

http://dx.doi.org/10.1007/s12031-013-0161-y

[6] Gouda, H.N., Sagoo, G.S., Harding, A.H., Yates, J., Sandhu, M.S. and Higgins, J.P.T. (2010) The Association between the Peroxisome Proliferator-Activated Receptor- $\gamma 2$ (PPARG2) Pro12Ala Gene Variant and Type 2 Diabetes Mellitus: A HuGE Review and Meta-Analysis. American Journal of Epidemiology, 171, 645-655. http://dx.doi.org/10.1093/aje/kwp450

[7] Grarup, N., Sandholt, C.H., Hansen, T. and Pedersen, O. (2014) Genetic Susceptibility to Type 2 Diabetes and Obesity: From Genome-Wide Association Studies to Rare Variants and Beyond. Diabetologia, 57, 1528-1541. http://dx.doi.org/10.1007/s00125-014-3270-4

[8] Liu, Y., Yuan, Z., Liu, Y., Zhang, J.J., Yin, P., Wang, D.Q., et al. (2007) PPAR Gamma Gene C161T Substitution Is Associated with Reduced Risk of Coronary Artery Disease and Decreased Proinflammatory Cytokine Expression. American Heart Journal, 154,718-724. http://dx.doi.org/10.1016/j.ahj.2007.06.009

[9] Tawfik, A., Sanders, T., Kahook, K., Akeel, S., Elmarakby, A. and Al-Shabrawey, M. (2009) Suppression of Retinal Peroxisome Proliferator-Activated Receptor Gamma in Experimental Diabetes and Oxygen-Induced Retinopathy: Role of NADPH Oxidase. Investigative Ophthalmology and Visual Science, 50, 878-884. http://dx.doi.org/10.1167/iovs.08-2005

[10] Muranaka, K., Yanagi, Y., Tamaki, Y., Usui, T., Kubota, N., Iriyama, A., et al. (2006) Effects of Peroxisome Proliferator-Activated Receptor $\gamma$ and Its Ligand on Blood Retinal Barrier in a Streptozotocin-Induced Diabetic Model. Investigative Ophthalmology and Visual Science, 47, 4547-4552. http://dx.doi.org/10.1167/iovs.05-1432

[11] Petrovic, M.G., Kunej, T., Peterlin, B., Dovc, P. and Petrovic, D. (2005) Gly482Ser Polymorphism of the Peroxisome Proliferator Activated Receptor- $\gamma$ Coactivator-1 Gene Might Be a Risk Factor for Diabetic Retinopathy in Slovene Population (Caucasians) with Type 2 Diabetes and the Pro12Ala Polymorphism of the PPAR $\gamma$ Gene Is Not. Diabetes Metabolism Research and Reviews, 21, 470-474. http://dx.doi.org/10.1002/dmrr.546

[12] Radha, V., Vimaleswaran, K.S., Babu, H.N., et al. (2006) Role of Genetic Polymorphism Peroxisome ProliferatorActivated Receptor- $\gamma 2$ Pro12Ala on Ethnic Susceptibility to Diabetes in South-Asian and Caucasian Subjects: Evidence for Heterogeneity. Diabetes Care, 29, 1046-1051. http://dx.doi.org/10.2337/dc05-1473

[13] Costa, V., Casamassimi, A., Esposito, K., et al. (2009) Characterization of a Novel Polymorphism in PPARG Regulatory Region Associated with Type 2 Diabetes and Diabetic Retinopathy in Italy. Journal of Biomedicine and Biotechnology, 2009, Article ID: 126917. http://dx.doi.org/10.1155/2009/126917

[14] Liu, D.X., Qi, H., Li, L.S. and Guo, J.C. (2008) Association of Peroxisome Proliferator-Activated Receptor- $\gamma$ Gene Pro12Ala and C161T Polymorphisms with Metabolic Syndrome. Circulation Journal, 72, 551-557. http://dx.doi.org/10.1253/circj.72.551

[15] Song, M.K., Roufogalis, B.D. and Huang, T.H. (2012) Modulation of Diabetic Retinopathy Pathophysiology by Natural Medicines through PPAR- $\gamma$-Related Pharmacology. British Journal of Pharmacology, 165, 4-19. http://dx.doi.org/10.1111/j.1476-5381.2011.01411.x

[16] Paracchini, V. and Taioli, E. (2005) Genetics of Leptin and Obesity: A HuGE Review. American Journal Epidemiology, 162, 101-114. http://dx.doi.org/10.1093/aje/kwi174

[17] Luan, J., Browne, P.O., Harding, A.H., Halsall, D.J., O’Rahilly, S., Chatterjee, V.K. and Wareham, N.J. (2001) Evidence for Gene-Nutrient Interaction at the PPAR Gamma Locus. Diabetes, 50, 686-689. http://dx.doi.org/10.2337/diabetes.50.3.686

[18] Thamer, C., Haap, M., Volk, A., et al. (2002) Evidence for Greater Oxidative Substrate Flexibility in Male Carriers of the Pro 12 Ala Polymorphism in PPAR- $\gamma 2$. Hormone and Metabolic Research, 34, 132-136. http://dx.doi.org/10.1055/s-2002-23196

[19] Luo, W., Cao, J., Li, J. and He, W. (2008) Adipose Tissue Specific PPAR Gamma Deficiency Increases Resistance to Oxidative Stress. Experimental Gerontology, 43, 154-163. http://dx.doi.org/10.1016/j.exger.2007.11.002

[20] Liu, L., Zheng, T., Wang, F., et al. (2010) Pro12Ala Polymorphism in the PPARG Gene Contributes to the Development of Diabetic Nephropathy in Chinese Type 2 Diabetic Patients. Diabetes Care, 33, 144-149. http://dx.doi.org/10.2337/dc09-1258

[21] Malecki, M.T., Cyganek, K., Mirkiewicz-Sieradzka, B., et al. (2008) Alanine Variant of the Pro12Ala Polymorphism of the PPAR $\gamma$ Gene Might Be Associated with Decreased Risk of Diabetic Retinopathy in Type 2 Diabetes. Diabetes Research and Clinical Practice, 80, 139-145. http://dx.doi.org/10.1016/j.diabres.2007.11.001

[22] Zietz, B., Barth, N., Spiegel, D., Schmitz, G., Schölmerich, J. and Schäffler, A. (2002) Pro12Ala Polymorphism in the Peroxisome Proliferator-Activated Receptor- $\gamma 2$ (PPAR $\gamma 2$ ) Is Associated with Higher Levels of Total Cholesterol and 
LDL-Cholesterol in Male Caucasian Type 2 Diabetes Patients. Experimental and Clinical Endocrinology and Diabetes, 110, 60-66. http://dx.doi.org/10.1055/s-2002-23487

[23] Chehaibi, K., Nouira, S., Mahdouani, K., Hamdi, S., Rouis, M. and Slimane, M.N. (2014) Effect of the PPAR $\gamma$ C161T Gene Variant on Serum Lipids in Ischemic Stroke Patients with and without Type 2 Diabetes Mellitus. Journal of Molecular Neuroscience, 54, 730-738. http://dx.doi.org/10.1007/s12031-014-0326-3

[24] Rooki, H., Haerian, M.S., Azimzadeh, P., et al. (2013) Distribution and Genotype Frequency of the C1431T and Pro12ala Polymorphisms of the Peroxisome Proliferator Activator Receptor Gamma Gene in an Iranian Population. Indian Journal of Human Genetics, 19, 423-429. http://dx.doi.org/10.4103/0971-6866.124370

[25] Yang, L.L., Hua, Q., Liu, R.K. and Yang, Z. (2009) Association between Two Common Polymorphisms of PPAR Gamma Gene and Metabolic Syndrome Families in a Chinese Population. Archives of Medical Research, 40, 89-96. http://dx.doi.org/10.1016/j.arcmed.2008.11.005

[26] Wang, X.L., Oosterhof, J. and Duarte, N. (1999) Peroxisome Proliferator-Activated Receptor Gamma C161 $\rightarrow$ T Polymorphism and Coronary Artery Disease. Cardiovascular Research, 44, 588-594. http://dx.doi.org/10.1016/S0008-6363(99)00256-4

[27] Blüher, M., Klemm, T., Gerike, T., Krankenberg, H., Schuler, G. and Paschke, R. (2002) Lack of Association between Peroxisome Proliferator-Activated Receptor-Gamma-2 Gene Variants and the Occurrence of Coronary Heart Disease in Patients with Diabetes Mellitus. European Journal of Endocrinology, 146, 545-551. http://dx.doi.org/10.1530/eje.0.1460545

[28] Wan, J., Xiong, S.X., Chao, S.P., et al. (2010) PPAR $\gamma$ Gene C161T Substitution Alters Lipid Profile in Chinese Patients with Coronary Artery Disease and Type 2 Diabetes Mellitus. Cardiovascular Diabetology, 9, 13. http://dx.doi.org/10.1186/1475-2840-9-13

[29] Ding, S., Liu, L., Zhuge, Q.C., Yu, Z., Zhang, X. and Xie, J. (2012) The Meta-Analysis of the Association of PPARG P12A, C161T Polymorphism and Coronary Heart Disease. Wiener klinische Wochenschrift, 124, 671-677. http://dx.doi.org/10.1007/s00508-012-0223-0

[30] Siezen, C.L., van Leeuwen, A.I., Kram, N.R., Luken, M.E., van Kranen, H.J. and Kampman, E. (2005) Colorectal Adenoma Risk Is Modified by the Interplay between Polymorphisms in Arachidonic Acid Pathway Genes and Fish Consumption. Carcinogenesis, 26, 449-457. http://dx.doi.org/10.1093/carcin/bgh336

[31] Jiang, J., Gajalakshmi, V., Wang, J., et al. (2005) Influence of the C161T but Not Pro12Ala Polymorphism in the Peroxisome Proliferator Activated Receptor Gamma on Colorectal Cancer in an Indian Population. Cancer Science, 96, 507-512. http://dx.doi.org/10.1111/j.1349-7006.2005.00072.x

[32] Shrestha, U.K., Karimi, O., Crusius, J.B., et al. (2009) Distribution of Peroxisome Proliferator-Activated ReceptorGamma Polymorphisms in Chinese and Dutch Patients with Inflammatory Bowel Disease. Inflammatory Bowel Diseases, 16, 312-319. http://dx.doi.org/10.1002/ibd.21059

[33] Tamaki, J., Iki, M., Morita, A., et al. (2010) Peroxisome Proliferator-Activated Receptor Gamma Polymorphism Is Related to Peak Bone Mass: The JPOS Study. Osteoporosis International, 21, 321-329. http://dx.doi.org/10.1007/s00198-009-0965-3

[34] Reiter, C.E., Wu, X., Sandirasegarane, L., et al. (2006) Diabetes Reduces Basal Retinal Insulin Receptor Signalling. Reversal with Systemic and Local Insulin. Diabetes, 55, 1148-1156. http://dx.doi.org/10.2337/diabetes.55.04.06.db05-0744

[35] Moffett, S.P., Feingold, E., Barmada, M.M., et al. (2005) The C161 $\rightarrow$ T Polymorphism in Peroxisome ProliferatorActivated Receptor Gamma, but Not P12A, Is Associated with Insulin Resistance in Hispanic and Non-Hispanic White Women: Evidence for Another Functional Variant in Peroxisome Proliferator-Activated Receptor Gamma. Metabolism, 54, 1552-1556. http://dx.doi.org/10.1016/j.metabol.2005.05.025

[36] Tavares, V., Hirata, R.D., Rodrigues, A.C., et al. (2005) Effect of the Peroxisome Proliferator-Activated ReceptorGamma C161T Polymorphism on Lipid Profile in Brazilian Patients with Type 2 Diabetes Mellitus. Journal of Endocrinological Investigations, 28, 129-136. http://dx.doi.org/10.1007/BF03345355

[37] Rhee, E.J., Oh, K.W., Lee, W.Y., et al. (2006) Effects of Two Common Polymorphisms of Peroxisome ProliferatorActivated Receptor- $\gamma$ Gene on Metabolic Syndrome. Archives of Medical Research, 37, 86-94. http://dx.doi.org/10.1016/j.arcmed.2005.04.008

[38] Meirhaeghe, A., Fajas, L., Helbecque, N., et al. (1998) A Genetic Polymorphism of the Peroxisome Proliferator-Activated Receptor Gamma Gene Influences Plasma Leptin Levels in Obese Humans. Human Molecular Genetics, 7, 435-440. http://dx.doi.org/10.1093/hmg/7.3.435

[39] Uckaya, G., Ozata, M., Bayraktar, Z., Erten, V., Bingol, N. and Ozdemir, C. (2000) Is Leptin Associated with Diabetic Retinopathy? Diabetes Care, 23, 371-376. http://dx.doi.org/10.2337/diacare.23.3.371

[40] Suganami, E., Takagi, H., Ohashi, H., et al. (2004) Leptin Stimulates Ischemia-Induced Retinal Neovascularization. 
Diabetes, 53, 2443-2448. http://dx.doi.org/10.2337/diabetes.53.9.2443

[41] Er, H., Doganay, S., Ozerol, E. and Yurekli, M. (2005) Adrenomedullin and Leptin Levels in Diabetic Retinopathy and Retinal Diseases. Ophthalmologica, 219, 107-111. http://dx.doi.org/10.1159/000083270

[42] Caramori, M.L., Canani, L.H., Costa, L.A. and Gross, J.L. (2003) The Human Peroxisome Proliferator-Activated Receptor $\gamma 2$ (PPAR $\gamma 2)$ Pro12Ala Polymorphism Is Associated with Decreased Risk of Diabetic Nephropathy in Patients with Type 2 Diabetes. Diabetes, 52, 3010-3013. http://dx.doi.org/10.2337/diabetes.52.12.3010

[43] Shah, A., Sheth, F., Majumder, A., et al. (2014) Effect of PPAR- $\gamma 2$ Gene Pro12Ala and ADR- $\beta 3$ Gene Trp64AArg Polymorphism on Glucose Homeostasis in Type 2 Diabetes Subjects from Western India. Molecular Cytogenetics, 7, 101. http://dx.doi.org/10.1186/1755-8166-7-S1-P101

[44] Bener, A., Zirie, M., Aoaa, H., Nawaz, Z., Samson, N. and Mohammad, R. (2015) Impact of the Pro12Ala Polymorphism of the PPAR 2 Gene on Diabetes and Obesity in a Highly Consanguineous Population. Indian Journal of Endocrinology and Metabolism, 19, 77-83. http://dx.doi.org/10.4103/2230-8210.131766

[45] Zhang, S., Gu, H. and Hu. N. (2015) Role of Peroxisome Proliferator-Activated Receptor $\gamma$ in Ocular Diseases. Journal of Ophthalmology, 2015, Article ID: 275435. http://dx.doi.org/10.1155/2015/275435 